\title{
The effect of climate on the net primary productivity (NPP) of Pinus koraiensis in the Changbai Mountains over the past 50 years
}

\author{
Ouya Fang ${ }^{1,2} \cdot$ Yang Wang ${ }^{1,2} \cdot$ Xuemei Shao ${ }^{1}$
}

Received: 29 January 2015/Revised: 10 September 2015/ Accepted: 22 September 2015/Published online: 3 October 2015

(c) Springer-Verlag Berlin Heidelberg 2015

\begin{abstract}
Key message The net primary productivity (NPP) of Pinus koraiensis, estimated from tree-ring widths, has a significant correlation with the minimum temperature in April and the summer precipitation over the past 50 years.

Abstract This study investigated the relationship between climate and Pinus koraiensis net primary productivity (NPP) (estimated using tree-ring widths) and the effect of climate on NPP in the Changbai Mountains. Three typical areas of Pinus koraiensis and a broad-leaved mixed forest were investigated and sampled. NPP was estimated using biomass equations and the annual diameter at breast height, calculated from tree-ring widths. A stepwise regression was used for the quantitative analysis of the response of NPP to climate variation, whereas correlation and response analyses were used to illustrate the relationship between the climatic variables and NPP. The results showed that between 1960 and 2012, the biomass of sampled Pinus koraiensis in the Changbai Mountains almost doubled, from 107.70 to $205.29 \mathrm{t} \mathrm{ha}^{-1}$. The NPP of Pinus koraiensis varied steadily within a confined range over the past 52 years, with an average of $1.88 \mathrm{t} \mathrm{ha}^{-1}$ year $^{-1}$. In this study, it was deduced that NPP was simultaneously
\end{abstract}

Communicated by J. Major.

Xuemei Shao

shaoxm@igsnrr.ac.cn

1 Key Laboratory of Land Surface Pattern and Simulation, Institute of Geographical Sciences and Natural Resources Research, Chinese Academy of Sciences, Beijing 100101, China

2 University of Chinese Academy of Sciences, Beijing 100049, China affected by temperature and precipitation. The minimum temperature in April and the precipitation in June and July, which most affected the changes in NPP, could explain $28.4 \%$ of the NPP variance. The extreme values of these principal climatic controls corresponded well with extreme NPP values. However, an increase in NPP caused by recent warming prior to the growing season might have been offset by a decrease in summer precipitation. Furthermore, the effect of temperature change on NPP was complex. An increase in monthly low temperatures induced by warming acted to increase NPP, while the monthly high temperatures during the growing season had a negative impact on NPP for the drought.

Keywords Tree-ring - NPP · Climate - Pinus koraiensis . Changbai Mountain

\section{Introduction}

Net primary productivity (NPP) is an indicator of plant growth and reflects their capacity to fix carbon via photosynthesis. Interactive effects of climatic variables on NPP are complex. The relationships between NPPs and climatic variables such as seasonal temperature and precipitation provide evidence for understanding the ecosystem responses to climate change (Luo et al. 2008; Raich et al. 2006). Over the past five decades, a significant warming of the global land surface (Hartmann et al. 2013) has resulted in a remarkable increase in the NPP of global ecosystems (Ciais et al. 2013; Nemani et al. 2003), especially savannas and temperate forests (Gang et al. 2013). Until recently, most evidence has shown an increase in the growth of temperate forests (Fang et al. 2005; Hasenauer et al. 1999; Nabuurs et al. 2003). A few cases have not shown any 
trends or have shown a decrease in productivity with extreme growth limitations (Lawrence et al. 2005; Lucht et al. 2002). Nunes et al. (2015) stated that the NPP of temperate Mediterranean forests (Pinus pinaster Aiton and Quercus pyrenaica Willd. forests) in northern Portugal will increase with a $\mathrm{CO}_{2}$ increase, whereas higher temperatures and lower soil moisture will result in an NPP decrease in the future. Because of the effect of photosynthesis/respiration on NPP, the day/night temperature contrast will directly affect NPP (Peng et al. 2013). Thus, if we are to determine the nature and extent of climatic effects on regional NPP, it will be necessary to study the inter-annual variability of regional NPP over the period for which instrumental climate data are available to develop an understanding of the inter-annual response of NPP to climate.

Three main approaches have been used in previous research to estimate forest NPP values: monitoring of sampling plots (Aragão et al. 2009; Clark et al. 2001; Fang et al. 1996), model simulations (Euskirchen et al. 2009; Stinson et al. 2011; Tian et al. 2010), and remote sensingbased estimation (Running et al. 2004; Zhang et al. 2009). Despite its high precision, the sampling plot approach is limited by the considerable workload and investigation period required. Models can be used to simulate long-term dynamic changes in regional NPP that are dependent on physiological and ecological processes, but reliable modeling requires laboratory or observational validation. Remote sensing is an effective method of monitoring vegetation indexes and can efficiently capture temporal and spatial changes in vegetation dynamics. However, the observation period and difficulties in species identification limit the accuracy of remote sensing when estimating changes in the NPP of forest species and communities. In fact, both the type and extent of the response to climatic variables differ among species in the same region. As a result of differences in species composition, the forest community NPP in the same climate zone responds differently to climate (Shanin et al. 2014). Therefore, research at a climate zone scale cannot reveal how climate drives dynamic changes in NPP in different forest communities. Therefore, exploring the response of forest NPP to climate change illustrates the need for the development of suitable methods.

It is well-known that ring-width data can be used to reflect the annual radial growth of trees. The strong relationship between different parts of a trunk (van der Maaten-Theunissen and Bouriaud 2012) and tree components (Luo 1996) confirms the reliability of estimating biomass increases using tree-ring data. Using the annual biomass increment derived from a ring-width series, Graumlich et al. (1989) made the first estimates of inter-annual NPP for dominant species in three vegetation zones (Tsuga heterophylla, Abies amabilis, and Tsuga chinensis) of the Cascade Mountain in western North America over the period 1880-1979. Their results showed that NPP was correlated with summer temperature and annual precipitation, but at different scales. In another study (Metsaranta and Kurz 2012), tree-ring data were used as a model input to identify the patterns and magnitude of the inter-annual variability of NPP of Pinus banksiana in western Canada. In other cases, the relationship between the tree-ring index and vegetation indexes was used to understand biomass changes in the past (Kaufmann et al. 2008; Liang et al. 2003, 2005; Chen et al. 2012). Therefore, ring-width data can be used to study the changes in NPP. In this study, the sampling plot approach was used with ring-width data to develop a method to reveal the dynamic changes in Pinus koraiensis NPP.

The primeval forest ecosystem in the Changbai Mountains is a well-preserved temperate mountain forest ecosystem in East Asia. The Pinus koraiensis and broadleaved mixed forest, which is one of the major forest vegetation types, has a significant effect on the carbon cycle and the carbon balance (Zhang et al. 2003) and is critical for climate regulation and maintenance of ecosystem balance (Xue et al. 1999; Zhao et al. 2004). Evidence (Liu et al. 2004; Wang et al. 2010) shows that the temperature has increased significantly over the past five decades in northeast China, resulting in a warming-drying trend since the 1970s (Hu et al. 2003; Liang et al. 2011; Wang et al. 2003). The wide application of remote sensing data has contributed to NPP estimation of forest communities in the Changbai Mountains (Huang et al. 2011; Zhao et al. 2012). The results of these previous studies indicate the vast climate and vegetation NPP database compiled for the Changbai Mountain Natural Reserve, which provides a reliable basis for comparison in this study.

Previous studies (Lin et al. 2013; Dai et al. 2013) showed that the forest productivity in the Changbai Mountains is very sensitive to climate warming. Using ring-width data from the Changbai Mountains, Wu and Shao (1996) first analyzed the changes in the annual biomass production of Larix olgensis in the background of global warming. Many research studies (Dai et al. 2013; Zhu et al. 2010; Huang et al. 2011; Zhou et al. 2011) have been carried out to investigate biomass and NPP using data from sampling plots or remote sensing, and the important controls on the growth of Pinus koraiensis have been explored.

This study uses tree-ring widths and sampling plot data to calculate the biomass and inter-annual NPP changes of Pinus koraiensis in Pinus koraiensis and broad-leaved mixed forests over a period of 50 years. The results are used to analyze the effects of long-term temperature and precipitation changes on the NPP of Pinus koraiensis. We 
aim to answer the following questions: (1) How has the biomass and NPP of Pinus koraiensis in the Changbai Mountains changed over the past 50 years? (2) What is the relationship between climatic variables and the NPP of Pinus koraiensis? (3) To what extent has the Pinus koraiensis NPP response been affected by climate?

\section{The study area}

The Changbai Mountains are at the intersection of the Neocathaysian system (the uplift belt along the East Asian continental margin) and the Yinshan tectonic belt. The Himalayan orogeny inherited the characteristics of the previous tectonic motion that accompanied volcanism in the Changbai Mountains.

The Changbai Mountain Natural Reserve $\left(41^{\circ} 41^{\prime} 49^{\prime \prime}\right.$ $42^{\circ} 51^{\prime} 18^{\prime \prime} \mathrm{N}, 127^{\circ} 42^{\prime} 55^{\prime \prime}-128^{\circ} 16^{\prime} 48^{\prime \prime} \mathrm{E}$; Fig. 1), established in 1961, is located in southeast Jilin Province, China. The forest ecosystem (the main protected element) is well protected to retain the original landscape. The vegetation distribution follows a well-defined vertical zonation, and has a rich species diversity. With increasing altitude, the vegetation changes from a low-mountain coniferous and broadleaf mixed forest zone $(500-1100 \mathrm{~m}$ asl) to a mountain coniferous forest zone $(1100-1800 \mathrm{~m}$ asl), a subalpine Betula ermanii forest zone (1800-2100 m asl), and an alpine tundra zone (>2100 m asl) (Xing 1988). The Changbai Mountains have a monsoon-influenced temperate continental mountain climate, with rainy and warm summers but cold, long winters (Chen et al. 2011). Over the period from 1982 to 2003, the annual average temperature in the Pinus koraiensis and broad-leaved mixed forest was $3.6{ }^{\circ} \mathrm{C}$, with a maximum value of $5.0{ }^{\circ} \mathrm{C}$ in 1998 and a minimum value of $2.5^{\circ} \mathrm{C}$ in 1984 . January is the coldest month, with a mean monthly temperature of $-15.6{ }^{\circ} \mathrm{C}$. July is the warmest month with a mean monthly temperature of $19.7^{\circ} \mathrm{C}$. The total annual precipitation of the Pinus koraiensis and broad-leaved mixed forest is $695.3 \mathrm{~mm}$; the maximum value of $983.8 \mathrm{~mm}$ occurred in 1986, and the minimum value of $510.4 \mathrm{~mm}$ occurred in 1999 (Zhang et al. 2005).

The Pinus koraiensis and broad-leaved mixed forest, which is found mainly on a lava plateau between 500 and $1100 \mathrm{~m}$ asl, is the most important forest vegetation type in the Changbai Mountains. The study area is located on the northern slopes of the Changbai Mountains at an altitude of $750 \mathrm{~m}$ asl in a typical Pinus koraiensis and broad-leaved mixed zone. The major species in the study areas are Pinus koraiensis, Tilia amurensis and Quercus mongolica, with a

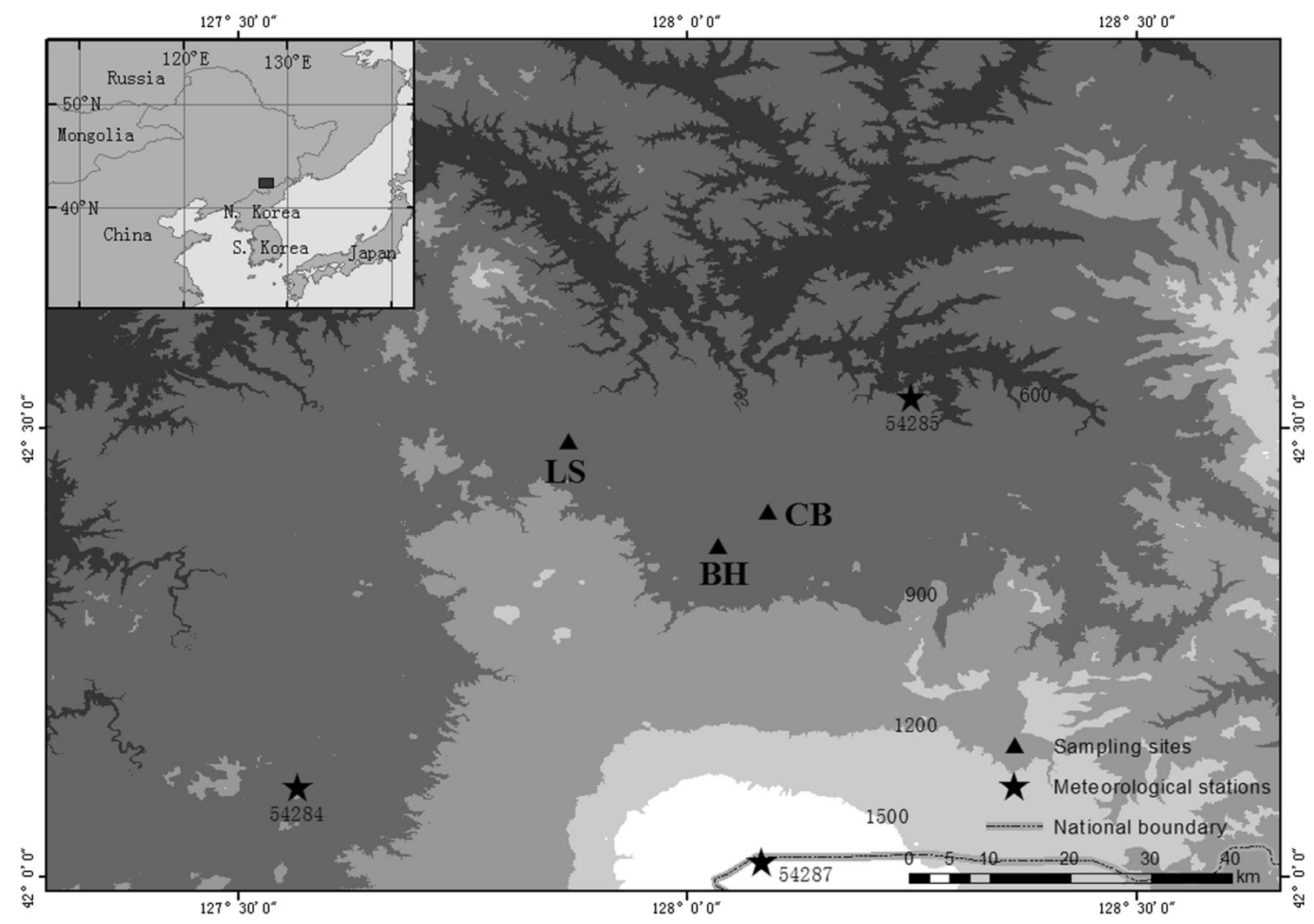

Fig. 1 The location of the study area. The study area showing the three sampling sites and meteorological stations. The background digital elevation data were provided by the International Scientific and Technical Data Mirror Site, Computer Network Information Center, Chinese Academy of Sciences (http://www.gscloud.cn) 
multi-layer forest stand and a fractional understory vegetation cover of $40 \%$.

\section{Data and methods}

\section{Climate data}

Data were obtained from Songjiang station $\left(42^{\circ} 32^{\prime} \mathrm{N}\right.$, $128^{\circ} 15^{\prime} \mathrm{E}$, at an altitude of $591.4 \mathrm{~m}$, station index number: 54285 ) because of its suitable location, altitude and slope (the station is only $20 \mathrm{~km}$ northeast of the sampling site (Fig. 1)). The climate data used in the analysis include monthly temperature $(T)$, monthly precipitation $(P)$, monthly maximum temperature $\left(T_{\max }\right)$, and monthly minimum temperature $\left(T_{\min }\right)$ for the period 1958-2012. The plants in the Pinus koraiensis and broad-leaved mixed forest begin to grow rapidly in April; prior to this date, their growth and activity are poor. The growing season is from May to August, when the increasing temperature results in vigorous plant growth. September is considered as the end of the growing season. The current growth is affected by the climatic conditions of the current year and previous years (Fritts 1976). For this reason, a 12-month period (October of the previous year to September of the current year) was selected for the statistical analysis.

\section{Sampling plot investigations and collection of tree-ring specimens}

Three typical sites with well-preserved vegetation were selected on the northern slopes of the Changbai Mountains, namely Yihaodi (CB), Baihe (BH), and Lushuihe (LS)
(Fig. 1; Table 1). A total of 3-5 sampling plots (each $20 \times 20 \mathrm{~m}$ ) separated by more than $200 \mathrm{~m}$ were established at each site. For each Pinus koraiensis tree included in these plots, the diameter at breast height (D) and total height $(\mathrm{H})$ were measured, and two core specimens were extracted at breast height (1.3 m above ground level). Any possible effect of the small slope on the cores was not considered here, and we simply drilled two cores in opposing directions. We collected increment cores towards the center of the tree to obtain as much pith as possible. Resampling was conducted if the inner arcs were invisible.

\section{Tree-ring processing and analysis}

After they were dried and mounted in the laboratory, the tree-ring specimens were sanded with 240- to 800-mesh abrasive paper until the xylem cells were clearly visible under a microscope. The ring widths were measured using a Lintab 6 tree-ring width measuring instrument (Rinntech, Heidelberg, Germany) (with a precision of $0.001 \mathrm{~mm}$ ) and simultaneously analyzed using the program TSAP-Win software (Rinn 2003). The quality of the cross-dating was confirmed statistically using the program COFECHA (Grissino-Mayer 2001), and the results of two specimens from the same tree were plotted using Matlab 2012b. The COFECHA and Matlab analysis was used to check the accuracy of the data, and specimens were re-examined if any inconsistencies in the width data were detected.

To estimate the ages of the trees, the rings at or close to the trunk center were used. The ages can be easily obtained by counting in the specimens with center rings. We considered the rings in the cross section of the stem as concentric circles. For the specimens with inner arcs of the

Table 1 Details of sampling plots

\begin{tabular}{|c|c|c|c|c|c|c|c|}
\hline Sampling plots & Altitude (m) & Longitude & Latitude & Slope $\left(^{\circ}\right)$ & Aspect & $\begin{array}{l}\text { Korean pine } \\
\text { Core/Tree }\end{array}$ & Dominant tree species ${ }^{\mathrm{a}, \mathrm{b}}$ \\
\hline CB1 & 739 & $128^{\circ} 5^{\prime} 12^{\prime \prime}$ & $42^{\circ} 24^{\prime} 10^{\prime \prime}$ & 5 & $\mathrm{~N}$ & $12 / 6$ & $\mathrm{Mo}, \mathrm{Kp}, \mathrm{Fm}$ \\
\hline CB2 & 755 & $128^{\circ} 5^{\prime} 45^{\prime \prime}$ & $42^{\circ} 24^{\prime} 10^{\prime \prime}$ & 4 & $\mathrm{~N}$ & $10 / 4$ & Mo, Kp, Tm \\
\hline CB3 & 751 & $128^{\circ} 5^{\prime} 49^{\prime \prime}$ & $42^{\circ} 24^{\prime} 10^{\prime \prime}$ & 5 & $\mathrm{~N}$ & $12 / 6$ & $\mathrm{Ta}, \mathrm{Kp}, \mathrm{Fm}$ \\
\hline CB4 & 764 & $128^{\circ} 5^{\prime} 2^{\prime \prime}$ & $42^{\circ} 24^{\prime} 42^{\prime \prime}$ & 3 & $\mathrm{~N}$ & $16 / 8$ & $\mathrm{Kp}, \mathrm{Cp}, \mathrm{Ta}$ \\
\hline CB5 & 749 & $128^{\circ} 5^{\prime} 6^{\prime \prime}$ & $42^{\circ} 24^{\prime} 41^{\prime \prime}$ & 4 & $\mathrm{~N}$ & $22 / 10$ & Mo, Kp, Тa \\
\hline BH1 & 773 & $128^{\circ} 2^{\prime} 0^{\prime \prime}$ & $42^{\circ} 22^{\prime} 6^{\prime \prime}$ & 1 & NW & $26 / 14$ & La, Kp, Mo \\
\hline $\mathrm{BH} 2$ & 770 & $128^{\circ} 2^{\prime} 3^{\prime \prime}$ & $42^{\circ} 21^{\prime} 54^{\prime \prime}$ & 1 & NW & $16 / 8$ & La, Kp, Mo \\
\hline $\mathrm{BH} 3$ & 766 & $128^{\circ} 2^{\prime} 6^{\prime \prime}$ & $42^{\circ} 22^{\prime} 18^{\prime \prime}$ & 1 & NW & $20 / 9$ & La, Kp, Mo \\
\hline LS1 & 758 & $127^{\circ} 52^{\prime} 6^{\prime \prime}$ & $42^{\circ} 29^{\prime} 6^{\prime \prime}$ & 1 & $\mathrm{~N}$ & $20 / 10$ & $\mathrm{Kp}, \mathrm{Mo}, \mathrm{Fm}$ \\
\hline $\mathrm{LS} 2$ & 753 & $127^{\circ} 52^{\prime} 6^{\prime \prime}$ & $42^{\circ} 29^{\prime} 4^{\prime \prime}$ & 1 & $\mathrm{~N}$ & $18 / 9$ & $\mathrm{Kp}, \mathrm{Fm}, \mathrm{Ap}$ \\
\hline LS3 & 797 & $127^{\circ} 52^{\prime} 2^{\prime \prime}$ & $42^{\circ} 29^{\prime} 6^{\prime \prime}$ & 2 & $\mathrm{~N}$ & $18 / 10$ & $\mathrm{Kp}, \mathrm{Ap}, \mathrm{Mo}$ \\
\hline
\end{tabular}

${ }^{a}$ Mo, Quercus mongolica; Kp, Pinus koraiensis; La, Larix olgensis; Fm, Fraxinus mandschurica; Tm, Tilia mandshurica; Ta, Tilia amurensis; $\mathrm{Cp}$, Cathay poplar; Ap, Acer pseudo-sieboldianum

b Tree species are ordered by basal area ratios of all species 
trunk, the distance from the specimen's innermost ring to the center of the circles, which represent the radius of the inner circle, was estimated using the measured arch height and chord length (Akachuku and Abolarin 1989). The average width of the measured inner 10 years was considered as the ring width of the internal missing rings. Tree age was estimated using the age of the innermost ring and the number of missing rings (Duncan 1989; Rozas 2003).

\section{Estimation of NPP}

The annual diameter at breast height was estimated using the following formula in which the diameter in 2012 represented the measured diameter $(D)$.

$D_{i}=D-2 \times \sum a_{i+1} \quad(i \leq 2011)$

where $i$ is the year, $a_{i}$ is the mean ring width in year $i$, and $D_{i}$ is the diameter at breast height in year $i$.

The annual tree height was calculated based on the diameter-height relationship for Pinus koraiensis (Zhang et al. 2010):

$H_{i}=27.063-\frac{470.765}{D_{i}+15.255}$

where $H_{i}$ is the tree height in year $i$. The measured tree heights from 2012 were compared with the calculated heights for the same year, and the results were not significantly different $(p<0.05)$.

Luo (1996) compiled data consisting of 1616 sample trees representing 180 tree species across China. A large number of additional investigation plots were established in the Changbai Mountains to estimate the total live biomass and NPP. The biomass allometric regression equations of Pinus koraiensis, which contained the diameter at breast height and tree height as variables, were based on the collected data and the biomass statistics of 134 sampling sites in northeast China (Table 2). Annual biomass, which refers to the standing crop in this study, was calculated from the sum of the parts:

$B_{i}=B_{s i}+B_{b i}+B_{l i}+B_{r i}$

where $B_{i}$ is the tree biomass in year $i$ and $B_{s i}, B_{b i}, B_{l i}$ and $B_{r i}$ represent the trunk biomass, branch biomass, leaf biomass, and root biomass in year $i$, respectively. Some components of biomass were neglected, such as fine litter- fall (shed leaves, twigs, fruits/flowers), losses to consumers (herbivory, frugivory, sap-sucking) and dead components. These elements contribute little to the total biomass and remain relatively unchanged over time (Dai et al. 2013).

The annual NPP was estimated using:

$\mathrm{NPP}_{i}=B_{i}-B_{i-1}$

where $\mathrm{NPP}_{i}$ is the NPP in year $i$. Pearson's correlation coefficients between NPP at different sites and between the NPP at different sites after calculating the first-order difference were then used to test the consistency of the NPP change across the study area.

\section{Statistical analysis}

The relationship between the monthly climatic variables and the NPP of Pinus koraiensis was investigated for the period 1961-2012 using Person's correlation coefficients generated by SPSS 19.0. The correlations between NPP and the climatic variables after calculating the first-order difference were used to determine whether the correlation coefficients accurately described the effect of each climatic variable on NPP. Then, the response function (Fritts 1976) from dendroclimatology was used to analyze the response of Pinus koraiensis NPP to changes in monthly temperature and precipitation.

In the response function, computed using the program Precon 32 (Fritts 1991), the climatic variables were transformed into principal components, and the key principal components and NPP were used in a regression analysis. The factors in the equation were independent of each other. The coefficients in the regression analysis were transformed into weights corresponding to the original data, which revealed the response of NPP to each climatic variable. On the other hand, the regression coefficients reflected the effects of the climatic variables on the NPP parameter. Bootstrapped response function analysis provided a means to evaluate the response of Pinus koraiensis NPP to climatic variables and to reveal the NPP response to these factors after the removal of between-factor interactions. Using Precon 32 with 500 re-samples, the NPP series was regressed onto orthogonal transformations of monthly precipitation and temperature from October of the previous year to September of the current year.

Table 2 Equations of each component of Korean pine (Luo 1996)

\begin{tabular}{llll}
\hline Trunk biomass $\left(B_{s}\right)$ & Branch biomass $\left(B_{\mathrm{b}}\right)$ & Leaf biomass $\left(B_{1}\right)$ & Root biomass $\left(B_{\mathrm{r}}\right)$ \\
\hline$B_{s}=0.023705\left(\mathrm{D}^{2} \mathrm{H}\right)^{0.966}$ & $B_{\mathrm{b}}=0.0138\left(\mathrm{D}^{2} \mathrm{H}\right)^{0.7304}$ & $B_{1}=0.0663\left(\mathrm{D}^{2} \mathrm{H}\right)^{0.5011}$ & $B_{\mathrm{r}}=0.027845\left(\mathrm{D}^{2} \mathrm{H}\right)^{0.885}$ \\
$(r=0.999, p<0.001)$ & $(r=0.978, p<0.001)$ & $(r=0.933, p<0.001)$ & $(r=0.913, p<0.01)$ \\
\hline
\end{tabular}


The climatic variables and the seasonal combination of climatic variables exceeding the 0.05 significance level in the response function were defined as the original factors in the stepwise regression analysis. The acceptance and rejection levels were 0.1 and 0.05 , respectively, and the quantitative result was shown by regression analysis, which indicated the extent of the impact of these factors.

The Mann-Kendall test, a nonparametric test that can be applied to a data set without missing values and to data that are not normally distributed, was used to test the rank of the observations and their time sequence (Hamed and Rao 1998; Kendall 1948; Mann 1945). To quantify whether the trends in major climatic variables and NPP were statistically significant, the Mann-Kendall test was applied. As some sequences might record significant changes, we correlated the major climatic variables and NPP for 30-year dated segments, with each successive segment offset by 1 year (e.g. 1961-1990, 1962-1991,...) to test the persistence of the correlation coefficients.

Finally, the effects of extreme climate conditions on NPP during this period were examined. Years with extreme climate values were compared with the corresponding NPP series to verify the direct relationship between climate and NPP. We analyzed when the lowest and highest levels of climatic variables appeared, discussed the responding mode of the NPP series, and validated the effects of these climatic variables on NPP.

\section{Results}

\section{Characteristics of climate change}

The climate data of Songjiang station collected since 1958 are shown in Fig. 2. The mean annual temperature in the study area changed significantly at a rate of $0.038{ }^{\circ} \mathrm{C}$ year $^{-1}$. The highest and lowest mean temperatures of 20 and $-17.8{ }^{\circ} \mathrm{C}$ occurred in July and in January, with increasing rates of 0.01 and $0.05{ }^{\circ} \mathrm{C}$ year ${ }^{-1}$, respectively. Furthermore, over the past 52 years, $T_{\max }$ and $T_{\min }$ followed different trends. $T_{\min }$ showed a significant upward trend, with an average increase of $0.065{ }^{\circ} \mathrm{C}$ year ${ }^{-1}$, whereas $T_{\max }$ showed little change. The average annual total precipitation, which showed no clear trend over the 52-year study period, had an average value of $675 \mathrm{~mm}$, and more than $80 \%$ of the annual precipitation fell from May to September.

\section{Biomass and NPP}

Slightly different age structures were found among the three research sites. The average age of Pinus koraiensis was greatest at LS (190 years), followed by CB
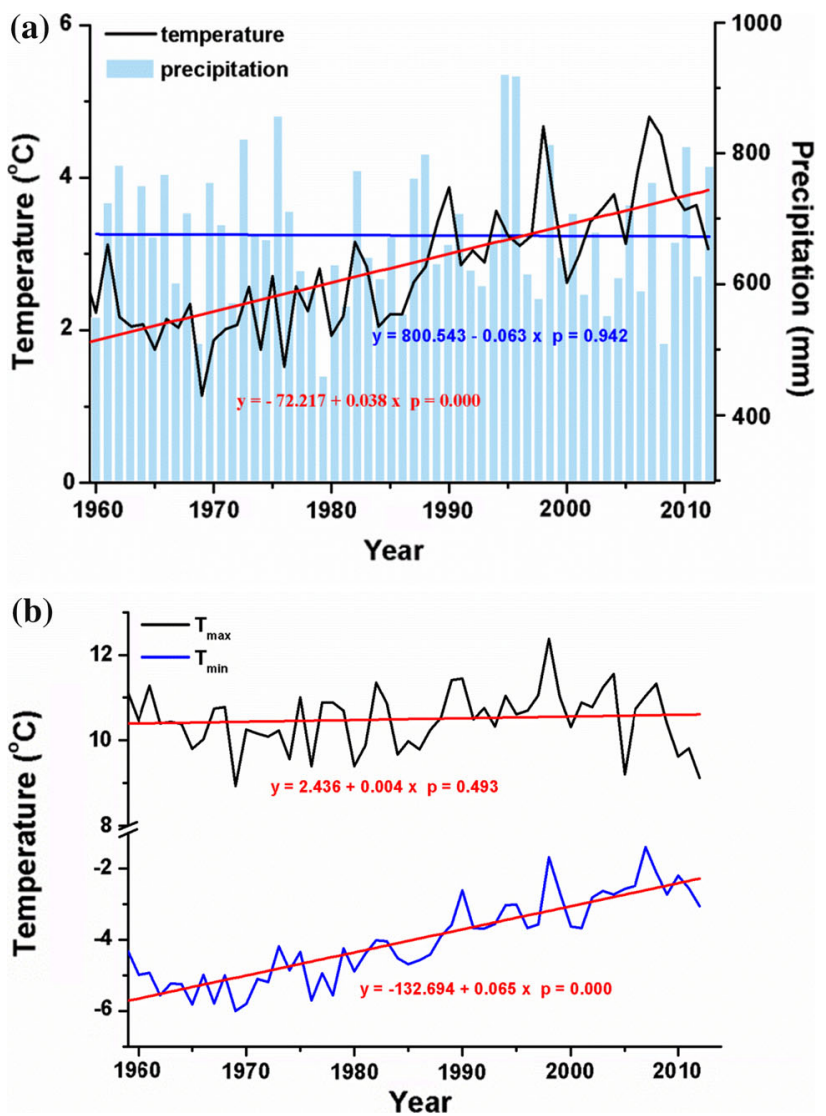

Fig. 2 a Mean annual temperature and precipitation, and $\mathbf{b}$ mean annual $T_{\max }$ and $T_{\min }$ at Songjiang Station from 1960 to 2012. A linear fit to temperature and precipitation data are shown by the red and blue lines, respectively. Mean annual temperature and $T_{\min }$ show a significant increase, but $T_{\max }$ and precipitation show no significant trend (color figure online)

(145.6 years) and BH (137 years). Among these sites, the age range was largest at LS (136-250 years). Analysis of the age-biomass relationships based on an exponential regression using the least square method indicated that the biomass of individual trees had an exponentially increasing relationship with increasing age (Fig. 3).

The biomass of Pinus koraiensis we sampled increased markedly at the three study sites between 1960 and 2012 . Biomass at LS increased from 184.51 to $332.75 \mathrm{t} \mathrm{ha}^{-1}$, with an average annual increment of $2.88 \mathrm{t} \mathrm{ha}^{-1}$, which was the fastest rate of increase among the three sites. At $\mathrm{CB}$, the biomass increased from 53.73 to $140.33 \mathrm{t} \mathrm{ha}^{-1}$, with an average annual increment of $1.71 \mathrm{t} \mathrm{ha}^{-1}$. At BH, the biomass increased from 84.87 to $142.77 \mathrm{t} \mathrm{ha}^{-1}$, with an average annual increment of $1.07 \mathrm{t} \mathrm{ha}^{-1}$. Based on an extrapolation of these sample values across the whole area, the biomass of Pinus koraiensis we sampled in the Changbai Mountains increased from 107.70 in 1960 to $205.29 \mathrm{t} \mathrm{ha}^{-1}$ in 2012, with an annual increment of $1.88 \mathrm{t}$ $\mathrm{ha}^{-1}$. 


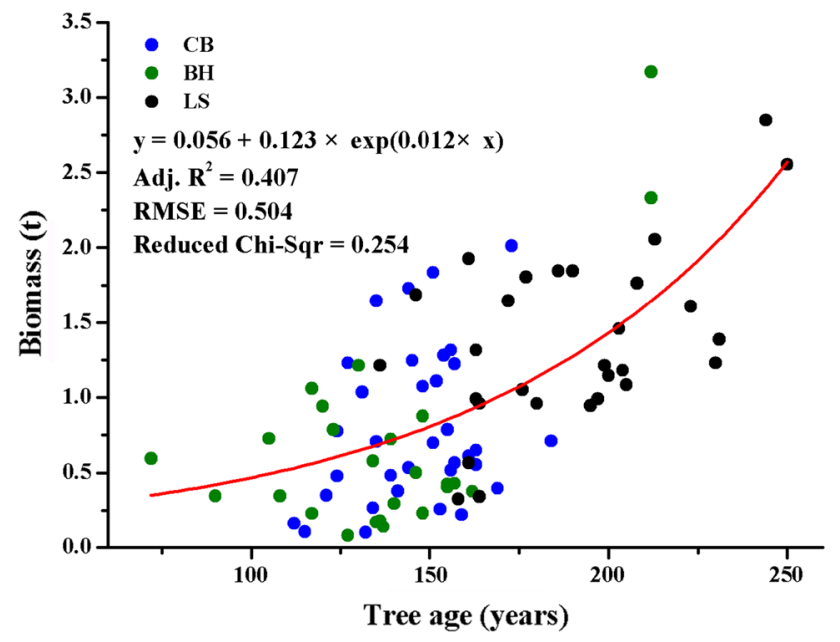

Fig. 3 Relationship between biomass and tree age at the three sample sites. An exponential curve (red line) is fitted to biomass data from all three sites bases on methods of least square and exponential smoothing (color figure online)

The NPP changes over the 52-year study period followed a similar pattern at all three study sites, and the maximum and minimum NPP years were concordant. The NPP of Pinus koraiensis showed a statistically insignificant increasing trend. The average NPP over the 52 years across all three sites was $1.88 \mathrm{t} \mathrm{ha}^{-1}$ year $^{-1}$. The lowest NPP value of $1.06 \mathrm{tha}^{-1}$ year $^{-1}$ occurred in 1965, and the peak value of $2.83 \mathrm{t} \mathrm{ha}^{-1}$ year $^{-1}$ occurred in 2008. Extreme minimum values occurred in 1965, 1988, 2000, and 2011, and extreme maximum values occurred in 1983, 1994, and 2008 (Fig. 7).

\section{Correlation and response functions}

The result of correlation analysis between NPP and the climatic variables showed that temperature played an important role in the growth of Pinus koraiensis over the study period. Temperature, especially $T_{\min }$ before the growing season in the current year, was strongly and positively correlated with the NPP variations. The correlation analysis revealed the different effects of $T_{\max }$ and $T_{\min }$ on NPP during the growing season. An increase in $T_{\max }$ during the growing season limited the growth of Pinus koraiensis, but an increase in $T_{\min }$ accelerated the growth of Pinus koraiensis. After applying the first difference transformation,NPP was significantly positively correlated with the mean temperature of the current April $(p<0.05)$. NPP was also positively correlated with the $T_{\min }$ of the current July $(p<0.05)$. However, the $T_{\max }$ of the current June and July had a slightly negative correlation with NPP (Fig. 4).

The correlation between seasonal temperature and NPP showed that the average temperature and $T_{\min }$ before the growing season were positively correlated $(p<0.05)$ with
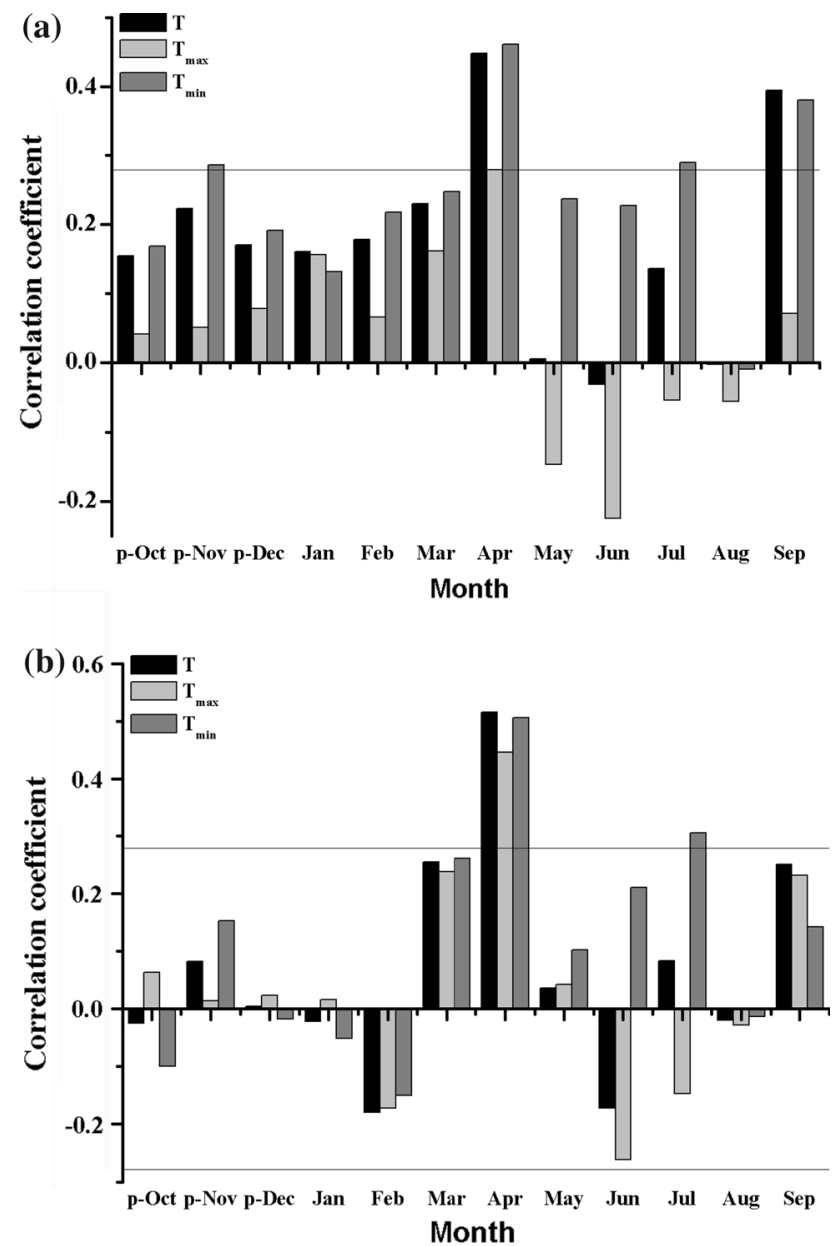

Fig. 4 a Correlations between temperature and NPP for the period 1961-2012, and b correlations between temperature and NPP after taking the first-order difference for the period 1961-2012. Gray line shows the 0.05 significance level. Temperature in current April is significantly positively correlated with NPP. In addition, $T_{\max }$ and $T_{\text {min }}$ have an opposing influence on NPP in summer

NPP. Combining our analysis of the temperature from May to July in the current year and NPP, a significantly positive $(p<0.05)$ correlation was found between $T_{\min }$ and NPP, but a negative ( $p=0.0053$ ) correlation was found between $T_{\max }$ and NPP. The correlation of NPP with precipitation was strongest in June and July, and the total precipitation in these 2 months was significantly positively correlated with NPP. After calculating the first-order difference, correlation analysis showed that precipitation in June and July was a major driver of the changes in NPP (Fig. 5).

In dendroclimatology research, a response function is often used to estimate the response of tree growth to climate change, and this method can also be used to estimate the NPP series based on the response of ring widths to climate. The response function coefficients revealed a very strong spring (especially April) temperature signal, and summer (especially June and July) precipitation signal 


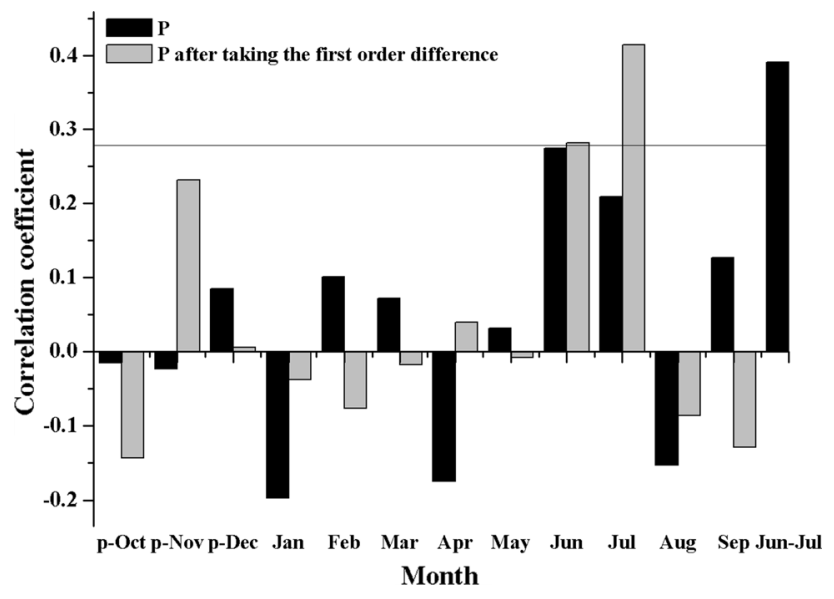

Fig. 5 Correlations between precipitation and NPP, and correlations after taking the first-order difference. Gray line shows the 0.05 significance level. Total precipitation in June and July is significantly positively correlated with NPP. Precipitation in June and July is significantly positively correlated with NPP after taking the first-order difference

(Fig. 6). The results showed that the temperature prior to the growing season (especially April) had a positive linear relationship with NPP. In contrast, the precipitation prior to the growing season had no significant relationship with NPP, but the precipitation in June and July had a positive linear relationship with NPP. Response analysis further indicated that $37.0 \%$ of the predicted variance could be attributed to temperature and precipitation from October in the previous year to September in the current year.

\section{Relationship between climate and NPP}

To quantify the relationship between climate and the NPP of the Pinus koraiensis and broad-leaved mixed forest in the Changbai Mountains, the monthly resolved climate linear regression functions between NPP and climatic variables were analyzed. The climatic variables and seasonal combinations that were significantly correlated with and had responded to NPP $(p<0.05)$ were included in the stepwise regression analysis. Consideration of the different regression equations (Table 3) showed that $T_{\min 4}\left(T_{\min }\right.$ in April) and $P_{67}$ (the total precipitation in June and July) well explained the change in NPP.

The NPP regression equation (Table 4)

$\mathrm{NPP}=1.674+0.090 T_{\min 4}+0.001 P_{67}$

showed that $T_{\min 4}$ and $P_{67}$ contributed $28.4 \%$ to the change in NPP (Table 3). $T_{\min 4}$ was the most important climatic control on NPP, which could explain $21.3 \%$ of the NPP change. Using Eq. 5, we then derived the NPP sequence from 1961 to 2012. A comparison with the actual NPP values showed that the NPP calculated using the
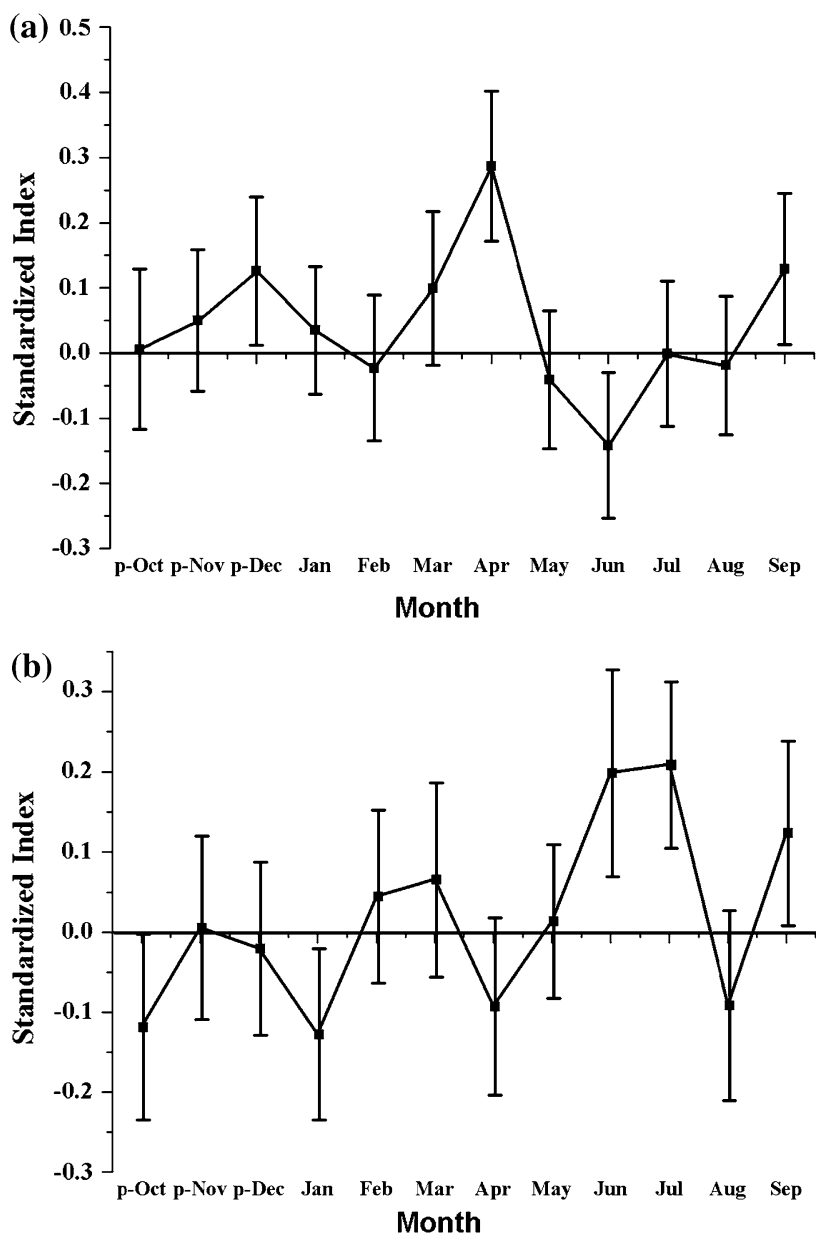

Fig. 6 Response coefficients plotted for the NPP response function for a temperature, and b precipitation. Error bars show $95 \%$ confidence limits for each coefficient; significant coefficients are those where the bars are either completely above or below the zero line

climatic variables closely reflected the actual annual NPP series (Fig. 7).

$T_{\min 4}$ increased significantly over the last half-century. The Mann-Kendall test confirmed that the mean value of $T_{\min 4}$ changed significantly in approximately 1980 . The value of $P_{67}$ fluctuated smoothly and $P_{6}$ declined from the 1990s onwards (Fig. 8a).

At a macro level, the increase in the $T_{\min 4}$ and $P_{67}$ would be expected to contribute to the development of NPP. As shown in Fig. 8b, the correlation between the main climatic variables and NPP changed for each 30-year segment that was analyzed. The correlation between NPP and $T_{\min 4}$ decreased and was not statistically significant $(p<0.05)$ during the middle of the studied period. At the same time, the effect of $P_{6}$ (precipitation in June) tended to intensify and indicated that the NPP of Pinus koraiensis was restricted primarily by water availability. In recent years, the correlation between NPP and $P_{7}$ (precipitation in July) 
Table 3 Summary of general linear models of the effects of $T_{\min 4}$ and $P_{67}$ on NPP
Table 4 Coefficients of the regression equation

\begin{tabular}{llllrl}
\hline Independent variable & $R^{2}$ & Adjusted $R^{2}$ & Std. error of the estimate & \multicolumn{1}{c}{$F$} & $p$ \\
\hline$T_{\min 4} P_{67}$ & 0.284 & 0.255 & 0.30304 & 9.736 & 0.000 \\
$T_{\min 4}$ & 0.213 & 0.197 & 0.31465 & 13.514 & 0.001 \\
$P_{67}$ & 0.153 & 0.136 & 0.32635 & 9.041 & 0.004 \\
\hline
\end{tabular}

The linear regression model with $T_{\min 4}$ and $P_{67}$ as independent variables explains $28.4 \%$ of the change in NPP. $T_{\min 4}$ and $P_{67}$ explain 21.3 and $15.3 \%$, respectively, of the change in NPP

\begin{tabular}{|c|c|c|c|c|c|}
\hline \multirow[t]{2}{*}{ Model } & \multicolumn{2}{|c|}{ Unstandardized coefficients } & \multirow[t]{2}{*}{ Standardized coefficients } & \multirow[t]{2}{*}{$t$} & \multirow[t]{2}{*}{ Sig. } \\
\hline & $B$ & Std. error & & & \\
\hline Constant & 1.674 & 0.210 & & 7.958 & 0.000 \\
\hline$T_{\min 4}$ & 0.090 & 0.030 & 0.379 & 2.998 & 0.004 \\
\hline$P_{67}$ & 0.001 & 0.001 & 0.280 & 2.214 & 0.031 \\
\hline
\end{tabular}

Regression equation is NPP $=1.674+0.090 T_{\min 4}+0.001 P_{67}$. All coefficients and constant exceed the $p<0.05$ significance level

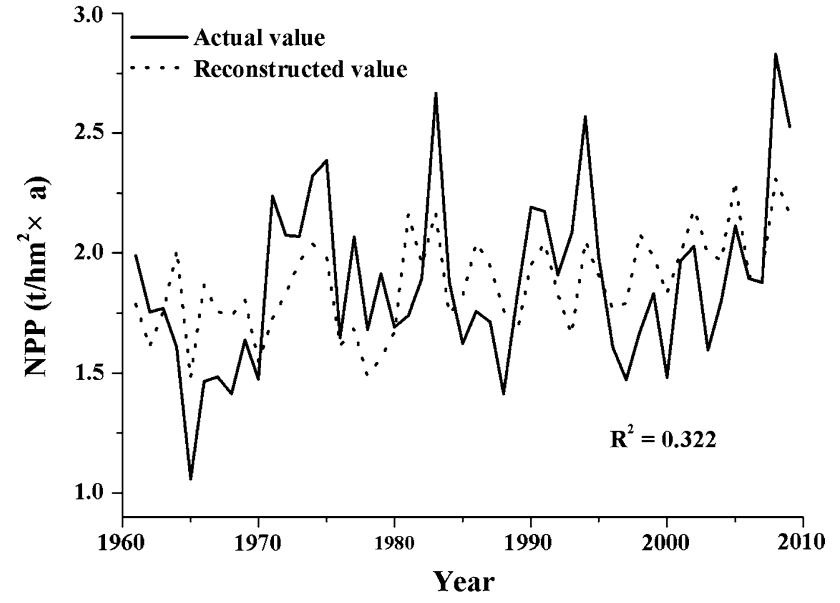

Fig. 7 The actual value and reconstructed value of NPP between 1961 and 2012. NPP sequence reconstructed by $T_{\min 4}$ and $P_{67}$ can explain $32.2 \%$ of the actual changes in NPP

decreased significantly, and NPP was limited mainly by $P_{6}$ and $T_{\min 4}$. The negative effect of the significant decrease in $P_{6}$ might have been partly offset by the positive effect of an increase in $T_{\min 4}$.

Comparative analysis showed that the $T_{\min 4}$ and $P_{67}$ values corresponded well with the fluctuations in NPP, especially the high-frequency variations. Extremely low and high values of NPP corresponded with extremely low and high values of $T_{\min 4}$ and $P_{67}$, respectively (Fig. 8a).

Since 1961, $T_{\min 4}$ showed a significant increasing trend. In $1965, T_{\min 4}$ reached its lowest value during the 52-year study period. In 2008, $T_{\min 4}$ reached its historic high, during a period of extreme high temperature events. Over
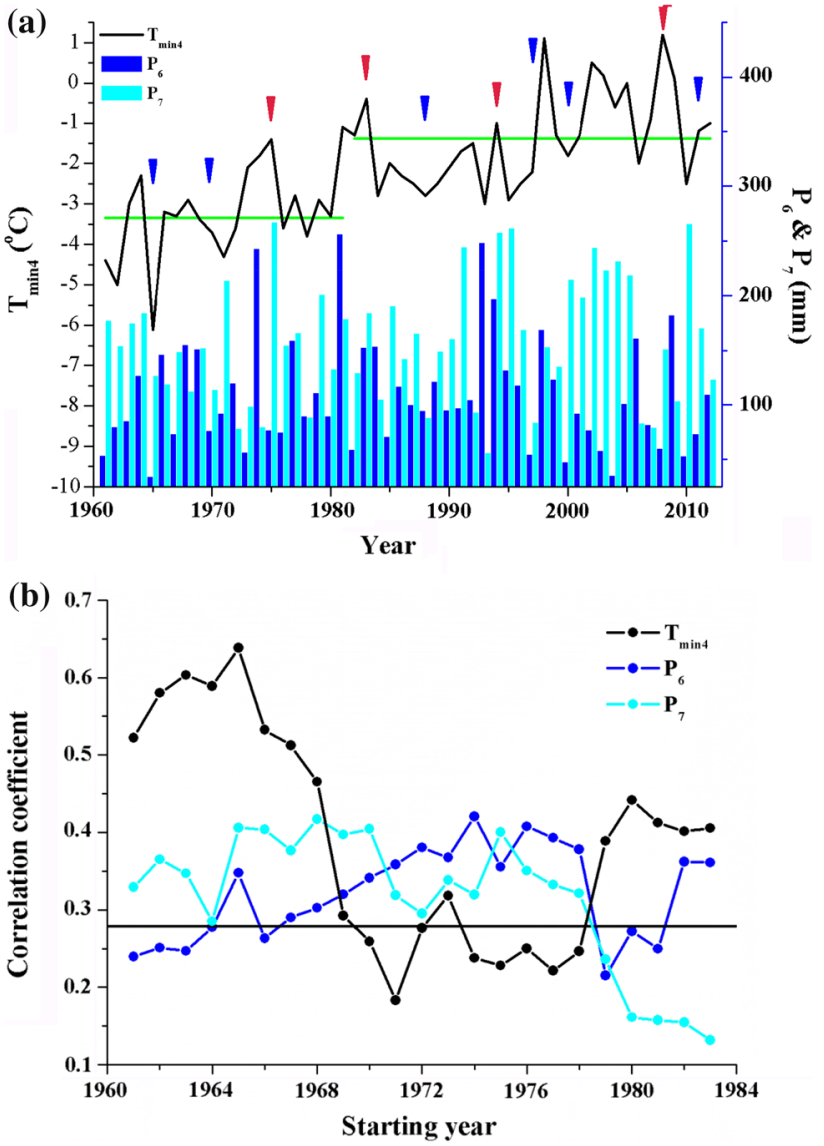

Fig. 8 a $T_{\min 4}, P_{6}$, and $P_{7}$ for the period between 1961 and 2012. The green line is average before and after mutations. The critical extremely high and low NPP years are indicated by red and blue triangles, respectively. b Correlations between NPP and climatic factors for the 30 -year dated segments, with a lag of 1 year (color figure online) 
the 52 years of this study, the NPP of Pinus koraiensis in the Changbai Mountains reached its lowest value in 1965, when $T_{\min 4}$ was at its lowest. NPP reached its highest value in 2008, when $T_{\min 4}$ was also at its highest. This result confirmed that $T_{\min 4}$ was one of the most important climatic variables with respect to changes in the NPP of Pinus koraiensis. The value of $P_{67}$ decreased to its lowest value in 1997, during a severe regional drought. NPP also showed an extremely low value in 1997 , although $T_{\min 4}$ was not low in that year. We infer that the minimal NPP value in 1997 was caused mainly by the restricted water supply during the summer drought. Thus, it can be observed that maximum or minimum values of NPP were closely related to climatic conditions during our study period.

\section{Discussion}

\section{Long-term trends in biomass and NPP}

The biomass of Pinus koraiensis we sampled in primary Pinus koraiensis and broad-leaved mixed forests in the Changbai Mountains nearly doubled from 107.70 in 1960 to $205.29 \mathrm{t} \mathrm{ha}^{-1}$ in 2012 , at an average rate of $1.88 \mathrm{t} \mathrm{ha}^{-1}$ year $^{-1}$. Because mortality and other losses could not be estimated in this study, the biomass and NPP were underestimated. Chen et al. (1987) estimated the biomass of Pinus koraiensis and broad-leaved mixed forests in the Changbai Mountains in 1983 and showed that the biomass of the trees was approximately $170.91 \mathrm{t} \mathrm{ha}^{-1}$ compared with a shrub biomass of approximately $1.90 \mathrm{t} \mathrm{ha}^{-1}$. Approximately, $18 \%$ of the total forest biomass is in the Pinus koraiensis trees. Jiang et al. (2005) estimated the biomass of 5 main tree species based on a 25-ha plot of Pinus koraiensis and broad-leaved mixed forests in the Changbai Mountains. The results showed that the biomass of Pinus koraiensis at $800 \mathrm{~m}$ asl was $81.01 \mathrm{t} \mathrm{ha}^{-1}$ in 2004. The results from other studies have confirmed the increase in tree biomass in the Pinus koraiensis and broad-leaved mixed forests in the Changbai Mountains. In this study, the biomass of Pinus koraiensis increased steadily, and although the rates of increase were slightly different among the sampling plots, they generally followed the same trend. Zhou et al. (2011) found that the average vegetation carbon storage in the Changbai Mountains increased from $233 \mathrm{t} \mathrm{C}$ $\mathrm{ha}^{-1}$ in 1981 to $317 \mathrm{t} \mathrm{C} \mathrm{ha}^{-1}$ in 2010 , which is consistent with our results.

In this study, the changes in the biomass of the trees we sampled were slightly different among the three sampling plots in the Pinus koraiensis and broad-leaved mixed forest. Of the three study sites, the proportion of Pinus koraiensis was the largest and its biomass increased the most rapidly at LS. The proportion of Pinus koraiensis was small at $\mathrm{CB}$ and $\mathrm{BH}$, but $\mathrm{CB}$ contained broad-leaved species with large sectional areas at breast height, and $\mathrm{BH}$ included some larches. The changing trends in the biomass of sampled Pinus koraiensis at $\mathrm{CB}$ and $\mathrm{BH}$ indicated that the biomass at $\mathrm{CB}$ may exceed that at $\mathrm{BH}$ in the future.

The Pinus koraiensis NPP fluctuated steadily over the past 52 years without showing a significant linear increase or decrease. The average NPP of the Pinus koraiensis sampled here was $1.88 \mathrm{t} \mathrm{ha}^{-1}$ year ${ }^{-1}$. The high- and lowfrequency changes in NPP were relatively consistent among the research sites. At all sites, NPP minima occurred in 1965, 1988, 2000, and 2011, whereas NPP maxima were recorded in 1983, 1994, and 2008. Qiu et al. (2014) estimated the annual increase in Pinus koraiensis NPP based on tree-ring chronology and relative growth formulae and showed that the correlations between climatic factors and NPP of Pinus koraiensis differed at different successional stages. The NPP of Pinus koraiensis in the primitive Pinus koraiensis and broad-leaved mixed forests increased to a peak value of approximately $0.8 \mathrm{t} \mathrm{ha}^{-1}$ year $^{-1}$ in 1960 and entered into a stationary phase thereafter. Although there have been few long-term studies on annual NPP changes of Pinus koraiensis, most of the research in NPP changes of forest communities in the Changbai Mountains has demonstrated the increasing trend of NPP of forest communities under the effect of climate change in recent decades. Fang et al. (2003) showed that the NPP of broadleaf and needle-leaf mixed forests in northeastern China increased significantly with an annual increase of $4.22 \mathrm{~g} \mathrm{C} \mathrm{m}^{-2} \mathrm{a}^{-1}$ over the period from 1982 to 1999. In a similar study, Zhao et al. (2012) used an improved individual-based forest ecosystem carbon budget model for China (FORCCHN) to show that changes in climate in the 1980s and 1990s led to increases in the NPP of various forests and the total NPP of northeastern China, especially in deciduous broad-leaved forests. These findings were subsequently confirmed using remotely sensing data. Sun and Mu (2014) showed the NPP response to various temperature-change scenarios along a north-south transect in eastern China. Using the conditional nonlinear optimal perturbation related to parameter (CNOP-P) approach, they found that the NPP decreased by $1.84 \%$ in northern China and increased by $4.09 \%$ in northeastern China.

\section{The effect of climate on NPP}

The cause-and-effect relationships between climatic variables and NPP cannot be explained through mathematical statistics. However, it is reasonable to reveal the relevance between the main climatic variables and the NPP changes of Pinus koraiensis in the Changbai Mountains, which can 
be helpful in exploring the impact of climate change on NPP.

Monthly temperatures before the growing season, especially $T_{\min 4}$, were positively correlated with the NPP series. For half a century, the $T_{\min 4}$ increased significantly whereas the NPP increase was not significant. We have reason to believe that the factors influencing the NPP of Pinus koraiensis in the Changbai Mountains are complicated. The result also showed that precipitation in the middle of the growing season (June and July) affected the NPP positively, which indicated that the NPP of Pinus koraiensis suffered greatly from water stress in summer. The reduction in precipitation in June since the 1990s may be the main reason for the slower increase in the NPP series. One possible explanation for the changing trend of NPP is that the positive effect of warming before the growing season is offset by the decrease in precipitation during the growing season.

To assess the climatic variables driving stem growth, Shao and Wu (1997) reconstructed January-April mean maximum temperatures of the Changbai Mountains from 1655 to 1993 based on the strong relationship between the temperatures and the ring width, which can represent the radial growth of trees. Similarly, Zhu et al. (2009) found that temperatures before the growing season were strongly correlated with the chronology of Pinus koraiensis, and they used a tree-ring index to reconstruct the temperatures from February to April in the Changbai Mountains. Yu et al. (2005) explored the relationship of Larix olgensis radial growth in the Changbai Mountains with climate change using dendrochronological techniques and proved that the mean temperature during April and May was significantly correlated with ring width at low elevation. In this study, the temperature prior to the growing season was confirmed to affect NPP, and the change in $T_{\min 4}$ explained $21.3 \%$ of the changes in NPP over the past 50 years. The slightly higher temperature prior to the growing season would increase the radial growth of the plant and the NPP in that year. Higher temperatures before the growing season promote snowmelt and increase the ground temperature, which is favorable for the accumulation of nutrients, and thereby promote the germination and growth of plant components (Kirdyanov et al. 2003; Vaganov et al. 1999).

Previous studies have demonstrated that Pinus koraiensis in the Pinus koraiensis and broad-leaved mixed forests in the Changbai Mountains are very sensitive to temperature. However, a 30-year study of a fixed plot in the Changbai Mountains (Dai et al. 2013) showed that the carbon stock in the old-growth Pinus koraiensis and broadleaved mixed forest increased at a rate of $1.79 \mathrm{t} \mathrm{ha}^{-1}$ over the period from 1981 to 2010 , but the climate warming over this period led to a loss of $0.96 \mathrm{t} \mathrm{ha}^{-1}$ in biological carbon storage, which showed that the effect of global warming on the carbon stock in the Changbai Mountains was not necessarily positive. The radial growth of Pinus koraiensis might be vulnerable to water stress due to climate warming and greater occurrence of drought. Similarly, the present results also showed that the changes in $T_{\max }$ during the growing season had a negative effect on NPP (Fig. 4). Extremely high temperatures during the growing season may negatively affect Pinus koraiensis NPP because of increased moisture stress (Harley et al. 2011), accelerated transpiration, and respiration (Lebourgeois et al. 2005). Moreover, the $T_{\max }$ and $T_{\min }$ during the growing seasons did not follow the same pattern over the past 52 years. Almost all monthly $T_{\min }$ values were positively correlated with the NPP of Pinus koraiensis. Yu et al. (2011) found that the high temperature during the growing season limited radial vegetation growth in low altitude areas in the Changbai Mountains. In contrast, the monthly minimum temperature in the growing season was positively correlated with NPP, indicating that the increase in monthly minimum temperature promoted vegetative growth. Photosynthesis, which mainly occurs during the daytime, is more sensitive to maximum daily temperature, whereas plant respiration occurs throughout the 24-h period and is affected by both maximum and minimum daily temperature. Consequently, plants respond differently to $T_{\max }$ and $T_{\min }$ (Peng et al. 2013).

Pinus koraiensis is water-loving tree species (Wei et al. 1995). The ubiquity of the volcanic pumice parent material in the Changbai Mountains and the widespread occurrence of pediment tableland albic soil have resulted in a light soil texture with a weak water-holding capacity. Precipitation in summer is proved to positively affect the NPP of Pinus koraiensis in the Changbai Mountains. Other researchers have drawn similar conclusions, i.e., that precipitation and the soil water content have a significant effect on the radial growth of Pinus koraiensis in the Changbai Mountains (Wang et al. 2001; Xiao et al. 2004). Previous studies (Dai et al. 2013; Yu et al. 2011) have shown that the radial growth of Pinus koraiensis was positively correlated with the Palmer drought severity index (PDSI) throughout the year, which confirms that water stress plays an important role in the growth of this species. Our results also showed that precipitation in the middle of the growing season (June and July) was significantly positively correlated with NPP. Similarly, Yu et al. (2013) confirmed that the NPP of Pinus koraiensis at altitudes of 800 and $1100 \mathrm{~m}$ asl in the Changbai Mountains is significantly and positively correlated with the PDSI in July. As a result of the presence of seasonal frozen layers in the Changbai Mountains, moisture excess is likely to occur during the cold season, and thus, from the end of the previous growing season to the period before the current growing season, the NPP of Pinus koraiensis is not significantly correlated with moisture levels. 
According to the correlation analysis between the precipitation in June-July and the NPP change for each 30-year segment (Fig. 8b), the correlation coefficients for $P_{7}$ and NPP decreased since the 1990s. NPP was mainly limited by $T_{\min 4}$ and $P_{6}$. However, $P_{6}$ showed a significant decreasing trend since the 1990s (Fig. 8a), which might be the main reason for the slower increase in NPP. Other studies reached similar conclusions. Mao et al. (2014) found that precipitation acted as the most important factor affecting forest NPP in this area and proved that evapotranspiration was closely correlated with NPP in coniferous forest, mixed coniferous broad-leaved forest, and broadleaved deciduous forest. Pretzsch et al. (2012) focused on the climatic effects on the productivity of Norway spruce and European beech in stands with different spatial mixing patterns and found that the high efficiency of water use could help plants grow. Because previous drought events restricted the NPP of Pinus koraiensis in the Changbai Mountains, an intense drought would slightly reduce the growth and carbon sequestration capacity of Pinus koraiensis. Therefore, the stable fluctuation of NPP over the past 50 years is mainly related to stable and decreasing precipitation under the situation of continual climate warming.

However, our limited knowledge about the optimum temperature and precipitation for Pinus koraiensis increases the uncertainty of the effects of climatic variables on NPP. The interaction between climate change, Pinus koraiensis NPP and the related physiological reasons should be explored. Controlled experiments and long-term observations can be helpful for understanding the responses of plants to global change. A 14-year controlled multifactor experiment was carried out in a temperate deciduous forest in the eastern part of the U.S. state of Tennessee (Hanson et al. 2005). These authors found that a change in precipitation considerably influenced the physiological adjustments of trees and resulted in a change in leaf biomass. Kardol et al. (2010) used 40-year observed data to analyze the effect of climate change, especially summer dryness, on forest dynamics, both at the species and community level. The shortage of the data makes it difficult to estimate if the original relationship between climatic variables and NPP would change under future climate scenarios.

\section{Summary}

Minimum temperature before the growing season and precipitation during the growing season appear to affect the NPP of Pinus koraiensis in the Changbai Mountains significantly. This study will assist future research on the NPP estimation and the community succession of Pinus koraiensis and broad-leaved mixed forests in the Changbai Mountains under a scenario of ongoing climate change.

Author contribution statement Ouya Fang analyzed the data and wrote the manuscript. She received guidance from Xuemei Shao. All the authors jointly designed the study and discussed the results.

Acknowledgments This research was supported by grants from the National Science-Technology Support Plan Projects (2012BAC19B02). The climate data were obtained from the China Meteorological Data Sharing Service System. We thank Eryuan Liang and Yunhe Yin for their helpful suggestions with this research, and Mingqi Li, Feng Chen and Yu Lan for field work assistance. We thank the staff at the tree-ring laboratory who participated in the processing of specimens.

\section{Compliance with ethical standards}

Conflict of interest The authors declare that they have no conflicts of interest.

\section{References}

Akachuku AE, Abolarin DAO (1989) Variations in pith eccentricity and ring width in teak (Tectona grandis L. F.). Trees-Struct Funct 3:111-116. doi:10.1007/bf01021074

Aragão L, Malhi Y, Metcalfe DB, Silva-Espejo JE, Jiménez E, Navarrete D, Almeida S, Costa A, Salinas N, Phillips OL, Anderson LO, Baker TR, Goncalvez PH, Huamán-Ovalle J, Mamai-Solórzano M, Meir P, Monteagudo A, Penuela MC, Prieto A, Quesada CA, Rozas-Dávila A, Rudas A, Silva Junior JA, Vásquez R (2009) Above-and below-ground net primary productivity across ten Amazonian forests on contrasting soils. Biogeosci Discuss 6:2441-2488

Chen BR, Ding GF, Xu GS, Zhang YH (1987) The nutrient cycling in the korean pine-broadleaved forest of the Changbai Mountains. Acta Pedol Sin 24:160-169

Chen L, Wu SH, Pan T (2011) Variability of climate-growth relationships along an elevation gradient in the Changbai Mountain, northeastern China. Trees-Struct Funct 25:1133-1139

Chen ZJ, Li JB, Fang KY, Davi NK, He XY, Cui MX, Zhang XL, Peng JJ (2012) Seasonal dynamics of vegetation over the past 100 years inferred from tree rings and climate in Hulunbei'er steppe, northern China. J Arid Environ 83:86-93. doi:10.1016/j. jaridenv.2012.03.013

Churakova OV, Eugster W, Zielis S, Cherubini P, Etzold S, Saurer M, Siegwolf R, Buchmann N (2014) Increasing relevance of spring temperatures for Norway spruce trees in Davos, Switzerland, after the 1950s. Trees-Struct Funct 28:183-191

Ciais P, Sabine C, Bala G, Bopp L, Brovkin V, Canadell J, Chhabra A, DeFries R, Galloway J, Heimann M, Jones C, Le Quéré C, Myneni RB, Piao S, Thornton P (2013) Carbon and other biogeochemical cycles. In: Climate change 2013: the physical science basis. Contribution of working group I to the fifth assessment report of the intergovernmental panel on climate change. Cambridge University Press, Cambridge, United Kingdom and New York, NY, USA

Clark DA, Brown S, Kicklighter DW, Chambers JQ, Thomlinson JR, $\mathrm{Ni} J$ (2001) Measuring net primary production in forests: concepts and field methods. Ecol Appl 11:356-370

Dai L, Jia J, Yu DP, Lewis BJ, Zhou L, Zhou WM, Zhao W, Jiang LH (2013) Effects of climate change on biomass carbon 
sequestration in old-growth forest ecosystems on Changbai Mountain in Northeast China. For Ecol Manag 300:106-116

D'Arrigo R, Jacoby GC, Fung IY (1987) Boreal forests and atmosphere-biosphere exchange of carbon dioxide. Nature 329:321-323

Duncan R (1989) An evaluation of errors in tree age estimates based on increment cores in kahikatea (Dacrycarpus dacrydioides). N Z Nat Sci 16:1-37

Euskirchen E, McGuire A, Chapin F III, Yi S, Thompson C (2009) Changes in vegetation in northern Alaska under scenarios of climate change, 2003-2100: implications for climate feedbacks. Ecol Appl 19:1022-1043

Fang JY, Liu GH, Xu SL (1996) Biomass and net production of forest vegetation in China. Acta Ecol Sin 16:497-508

Fang JY, Piao SL, Field CB, Pan YD, Guo QH, Zhou LM, Peng CH, Tao S (2003) Increasing net primary production in China from 1982 to 1999. Front Ecol Environ 1:293-297

Fang JY, Oikawa T, Kato T, Mo WH, Wang ZH (2005) Biomass carbon accumulation by Japan's forests from 1947 to 1995. Glob Biogeochem CY. doi:10.1029/2004GB002253

Fritts HC (1976) Tree rings and climate. Academic Press, New York

Fritts HC (1991) Reconstructing large-scale climatic patterns from tree-ring data: $t$ diagnostic analysis. University of Arizona Press, Arizona

Gang CC, Zhou W, Li JL, Chen YZ, Mu SJ, Ren JZ, Chen JM, Groisman PY (2013) Assessing the spatiotemporal variation in distribution, extent and NPP of terrestrial ecosystems in response to climate change from 1911 to 2000. Plos One 9(8):e80394

Graumlich LJ, Brubaker LB, Grier CC (1989) Long-term trends in forest net primary productivity: Cascade Mountains, Washington. Ecology 70(2):405-410

Grissino-Mayer HD (2001) Evaluating crossdating accuracy: a manual and tutorial for the computer program COFECHA. Tree-ring Res 57:205-221

Hamed KH, Rao AR (1998) A modified Mann-Kendall trend test for autocorrelated data. J Hydrol 204:182-196

Hanson PJ, Wullschleger SD, Norby RJ, Tschaplinski TJ, Gunderson CA (2005) Importance of changing CO2, temperature, precipitation, and ozone on carbon and water cycles of an upland-oak forest: incorporating experimental results into model simulations. Glob Change Biol 11:1402-1423

Harley GL, Grissino-Mayer HD, Horn SP (2011) The dendrochronology of Pinus elliottii in the lower Florida Keys: chronology development and climate response. Tree-Ring Res 67:39-50

Hartmann DL, Tank AMGK, Rusticucci M, Alexander LV, Brönnimann S, Charabi Y, Dentener FJ, Dlugokencky EJ, Easterling DR, Kaplan A, Soden BJ, Thorne PW, Wild M, Zhai PM (2013) Observations: atmosphere and surface. In: Climate change 2013: the physical science basis. Contribution of working group I to the fifth assessment report of the intergovernmental panel on climate change. Cambridge University Press, Cambridge, United Kingdom and New York, NY, USA

Hasenauer H, Nemani RR, Schadauer K, Running SW (1999) Forest growth response to changing climate between 1961 and 1990 in Austria. For Ecol Manag 122:209-219

Hu ZZ, Yang S, Wu R (2003) Long-term climate variations in China and global warming signals. J Geophys Res 108:4614

Huang F, Qi X, Xu SL (2011) Monitoring NPP changes in Changbai Mountain area, China with MODIS images. In: Geoinformatics, 2011 19th international conference on Shanghai, pp 1-4

Jiang P, Ye J, Wu G (2005) Woody species composition and biomass of main tree species in a $25 \mathrm{hm} 2$ plot of broad-leaved and Korean pine mixed forests of Changbai Mountain, northeast China. J Beijing For Univ 27:112-115
Kardol P, Todd DE, Hanson PJ, Mulholland PJ (2010) Long-term successional forest dynamics: species and community responses to climatic variability. J Veg Sci 21:627-642

Kaufmann R, D'Arrigo R, Paletta L, Tian H, Jolly WM, Myneni R (2008) Identifying climatic controls on ring width: the timing of correlations between tree rings and NDVI. Earth Interact 12:1-14

Kendall MG (1948) Rank correlation methods. Hafner Publishing, Oxford

Kirdyanov A, Hughes M, Vaganov E, Schweingruber F, Silkin P (2003) The importance of early summer temperature and date of snow melt for tree growth in the Siberian Subarctic. Trees-Struct Funct 17:61-69

Lawrence GB, Lapenis AG, Berggren D, Aparin BF, Smith KT, Shortle WC, Bailey SW, Varlyguin DL, Babikov B (2005) Climate dependency of tree growth suppressed by acid deposition effects on soils in Northwest Russia. Environ Sci Technol 39:2004-2010

Lebourgeois F, Bréda N, Ulrich E, Granier A (2005) Climate-treegrowth relationships of European beech (Fagus sylvatica L.) in the French permanent plot network (RENECOFOR). TreesStruct Funct 19:385-401

Liang EY, Vennetier M, Lin JX, Shao XM (2003) Relationships between tree increment, climate and above-ground biomass of grass: a case study in the typical steppe, north China. Acta Oecol 24:87-94

Liang EY, Shao XM, He JC (2005) Relationships between tree growth and NDVI of grassland in the semi-arid grassland of north China. Int J Remote Sens 26:2901-2908. doi:10.1080/ 01431160500056931

Liang LQ, Li LJ, Liu Q (2011) Precipitation variability in Northeast China from 1961 to 2008. J Hydrol 404:67-76

Lin B, Xu QQ, Liu WH, Zhang GC, Xu QY, Liu QJ (2013) Dendrochronology-based stand growth estimation of Larix olgensis forest in relation with climate on the eastern slope of Changbai Mountain, NE China. Front Earth Sci 7:429-438

Liu BH, Xu M, Henderson M, Qi Y, Li YQ (2004) Taking China's temperature: daily range, warming trends, and regional variations, 1955-2000. J Clim 17:4453-4462

Lucht W, Prentice IC, Myneni RB, Sitch S, Friedlingstein P, Cramer W, Bousquet P, Buermann W, Smith B (2002) Climatic control of the high-latitude vegetation greening trend and Pinatubo effect. Science 296:1687-1689

Luo TX (1996) Patterns of net primaty productivity for Chinese major forest types and their mathematical models. Institute of Geographic Sciences and Natural Resources Research, CAS

Luo YQ, Gerten D, Le Maire G, Parton WJ, Weng ES, Zhou XH, Keough C, Beier C, Ciais P, Cramer W, Dukes JS, Emmett B, Janson PJ, Alan K, Linder S, Nepstad D, Rustad L (2008) Modeled interactive effects of precipitation, temperature, and $\mathrm{CO}_{2}$ on ecosystem carbon and water dynamics in different climatic zones. Glob Change Biol 14(9):1986-1999

Mann HB (1945) Nonparametric tests against trend. Econometrica J Econom Soc 13(3):245-259

Mao DH, Wang ZM, Wu CS, Song KS, Ren CY (2014) Examining forest net primary productivity dynamics and driving forces in northeastern China during 1982-2010. Chin Geogr Sci 24:1-16

Metsaranta J, Kurz W (2012) Inter-annual variability of ecosystem production in boreal jack pine forests (1975-2004) estimated from tree-ring data using CBM-CFS3. Ecol Model 224:111-123

Nabuurs GJ, Schelhaas MJ, Field CB (2003) Temporal evolution of the European forest sector carbon sink from 1950 to 1999. Glob Change Biol 9:152-160

Nemani RR, Keeling CD, Hashimoto H, Jolly WM, Piper SC, Tucker CJ, Myneni RB, Running SW (2003) Climate-driven increases in 
global terrestrial net primary production from 1982 to 1999 . Science 300:1560-1563

Nunes L, Gower ST, Peckham SD, Magalhaes M, Lopes D, Rego FC (2015) Estimation of productivity in pine and oak forests in northern Portugal using Biome-BGC. Forestry 88:200-212

Peng SS, Piao SL, Ciais P, Myneni RB, Chen AP, Chevallier F, Dolman AJ, Janssens IA, Peñuelas J, Zhang GX, Vicca S, Wan SQ, Wang SP, Zeng H (2013) Asymmetric effects of daytime and night-time warming on Northern Hemisphere vegetation. Nature 501:88-92

Poulter B, Pederson N, Liu HY, Zhu ZC, D'Arrigo R, Ciais P, Davi N, Frank D, Leland C, Myneni R, Piao SL, Wang T (2013) Recent trends in Inner Asian forest dynamics to temperature and precipitation indicate high sensitivity to climate change. Agr For Meteorol 178:31-45

Pretzsch H, Dieler J, Seifert T, Rötzer T (2012) Climate effects on productivity and resource-use efficiency of Norway spruce (Picea abies [L.] Karst.) and European beech (Fagus sylvatica [L.]) in stands with different spatial mixing patterns. TreesStruct Funct 26:1343-1360

Qiu Y, Gao LS, Zhang X, Guo J, Ma ZY (2014) Effect of climate change on net primary productivity of Korean pine (Pinus koraiensis) at different successional stages of broad-leaved Korean pine forest. Chin J Appl Ecol 25:1870-1878

Raich JW, Russell AE, Kitayama K, Parton WJ, Vitousek PM (2006) Temperature influences carbon accumulation in moist tropical forests. Ecology 87(1):76-87

Rozas V (2003) Tree age estimates in Fagus sylvatica and Quercus robur: testing previous and improved methods. Plant Ecol 167:193-212

Running SW, Nemani RR, Heinsch FA, Zhao MS, Reeves M, Hashimoto H (2004) A continuous satellite-derived measure of global terrestrial primary production. Bioscience 54:547-560

Shanin V, Komarov A, Makipaa R (2014) Tree species composition affects productivity and carbon dynamics of different site types in boreal forests. Eur J For Res 133:273-286

Shao XM, Wu XD (1997) Reconstruction of climate change on Changbai Mountain, northeast China using tree-ring data. Quat Sci $1: 76-85$

Stinson G, Kurz WA, Smyth CE, Neilson ET, Dymond CC, Metsaranta JM, Boisvenue C, Rampley GJ, Li Q, White TM, Blain D (2011) An inventory-based analysis of Canada's managed forest carbon dynamics, 1990 to 2008. Glob Change Biol 17:2227-2244

Sun GD, Mu M (2014) The analyses of the net primary production due to regional and seasonal temperature differences in eastern China using the LPJ model. Ecol Model 289:66-76

Rinn F (2003) TSAP-WIN: time series analysis and presentation for dendrochronology and related applications. Rinntech, Heidelberg

Tian HQ, Chen GS, Liu ML, Zhang C, Sun G, Lu CQ, Xu XF, Ren W, Pan SF, Chappelka A (2010) Model estimates of net primary productivity, evapotranspiration, and water use efficiency in the terrestrial ecosystems of the southern United States during 1895-2007. For Ecol Manag 259:1311-1327

Vaganov E, Hughes M, Kirdyanov A, Schweingruber F, Silkin P (1999) Influence of snowfall and melt timing on tree growth in subarctic Eurasia. Nature 400:149-151

van der Maaten-Theunissen M, Bouriaud O (2012) Climate-growth relationships at different stem heights in silver fir and Norway spruce. Can J For Res 42:958-969

Wang M, Dai LM, Ji LZ (2001) A preliminary study on ecological response of dominant tree species in Korean pine broadleaf forest at Changbai Mountain to soil water stress and their biomass allocation. J Appl Ecol 12:496-500

Wang SL, Zhuang LW, Wang FT (2003) Impact of climate warming on thermal and moisture conditions in northeast China in recent 20 years. Q J Appl Meteorol 2:002
Wang SP, Wang ZH, Piao SL, Fang JY (2010) Regional differences in the timing of recent air warming during the past four decades in China. Chin Sci Bull 55:1968-1973

Wei L, Wang HM, Wang QD, Liu YF, He QT, Yuan JZ, Shao H, Song CH (1995) The influence of climate changes on Korean pine forest in China. Geogr Res 14:17-26

Wu XD, Shao XM (1996) A preliminary study on impact of climate change on tree growth using tree ring-width data. Acta Geogr Sin $51: 92-101$

Xiao DM, Wang M, Ji LZ (2004) Influence of water stress on growth and biomass allocation of dominant tree species in mixed forest of broad-leaved and Korean pine at Changbai Mountain. Chin J Ecol 5:017

Xing SP (1988) Jilin forest. Jilin Science and Technology Press, Changchun

Xue DY, Bao HS, Li WH (1999) A valuation study on the indirect values of forest ecosystem in Changbaishan Mountain biosphere reserve of China. China Environ Sci 19:247-252

Yu DP, Wang SZ, Tang L, Dai LM, Wang QL, Wang SX (2005) Relationship between tree-ring chronology of Larix olgensis in Changbai Mountains and the climate change. J Appl Ecol 16:14-20

Yu DP, Wang QW, Wang Y, Zhou WM, Ding H, Fang XM, Jiang SW, Dai LM (2011) Climatic effects on radial growth of major tree species on Changbai Mountain. Ann For Sci 68:921-933

Yu DP, Liu JQ, Benard JL, Zhou L, Zhou WM, Fang XM, Wei YW, Jiang SW, Dai LM (2013) Spatial variation and temporal instability in the climate-growth relationship of Korean pine in the Changbai Mountain region of Northeast China. For Ecol Manag 300:96-105

Zhang N, Yu GR, Zhao SD, Yu ZL (2003) Carbon budget of ecosystem in Changbai Mountain natural reserve. Environ Sci $24: 24-32$

Zhang M, Guan DX, Han SJ, Wu J, Zhang J, Jin M, Xu H, He X, Dai $G$ (2005) Climatic dynamics of broadleaved Korean pine forest in Changbai Mountain during the last 22 years. Chin J Ecol 24:1007-1012

Zhang YJ, Xu M, Chen H, Adams J (2009) Global pattern of NPP to GPP ratio derived from MODIS data: effects of ecosystem type, geographical location and climate. Glob Ecol Biogeogr 18:280-290

Zhang ZW, Kang XG, Yang H, Feng QX, Yao JC (2010) Optimal volume equations for three major coniferous tree species in Changbai Mountains. J Northwest For Univ 25:144-150

Zhao TQ, Ouyang ZY, Zheng H, Wang XK, Miao H (2004) Forest ecosystem services and their valuation in China. J Nat Resour 19:480-491

Zhao JF, Yan XD, Guo JP, Jia GS (2012) Evaluating spatial-temporal dynamics of net primary productivity of different forest types in Northeastern China based on improved FORCCHN. Plos One. doi:10.1371/journal.pone.0048131

Zhou L, Dai LM, Wang SX, Huang XT, Wang XC, Qi L, Wang QW, Li GW, Wei YW, Shao GF (2011) Changes in carbon density for three old-growth forests on Changbai Mountain, Northeast China: 1981-2010. Ann For Sci 68:953-958

Zhu HF, Fang XQ, Shao XM, Yin ZY (2009) Tree ring-based February-April temperature reconstruction for Changbai Mountain in Northeast China and its implication for East Asian winter monsoon. Clim Past 5:661-666

Zhu B, Wang XP, Fang JY, Piao SL, Shen HH, Zhao SQ, Peng CH (2010) Altitudinal changes in carbon storage of temperate forests on Mt Changbai, Northeast China. J Plant Res 123:439-452 